\title{
EDITORIAL
}

Norma Seltzer Goldstein

Universidade de São Paulo, São Paulo, SP, Brasil

Ana Elvira Luciano Gebara

Universidade Cruzeiro do Sul e Fundação Getúlio Vargas, São Paulo, SP, Brasil

Maria Inês Batista Campos

Universidade de São Paulo, São Paulo, SP, Brasil

\section{Leitura: abrangência e estratégias}

Por um lado, o texto é apenas uma partitura e, por outro, são as capacidades dos leitores, individualmente diferenciados, que instrumentam a obra.

O texto se completa quando o seu sentido é constituído pelo leitor.

Wolfgang Iser

"Literatura, Artes e Ensino: Confluências?” tema deste número 30/2 de 2017 de Linha d'Água inspira-se no trabalho desenvolvido pela homenageada desta edição: Professora Nelly Novaes Coelho. Vista não apenas como pesquisadora da literatura voltada a jovens leitores, cuja atuação resultou em contribuição significativa no espaço acadêmico, mas também como docente que inspirou e orientou trabalhos nessa área. É dessa maneira que ela é apresentada em seu perfil acadêmico, no primeiro artigo da publicação, por seus ex-orientandos Maria Zilda Cunha e Cristiano Camilo Lopes.

Embora a literatura infantil seja recente no meio acadêmico, desde que se estabeleceu como área, foi objeto de linhas de pesquisa e de estudos, na perspectiva iniciada pela professora Nelly e em outras, resultando em obras fundamentais 
Linha D’Água (Online), São Paulo, v. 30, n. 2, p. 1-7, out. 2017

sobre o tema, que tem se renovado em reflexões como a resenhada, no texto final desta edição, por Geovana Gentili Santos: LAJOLO, M.; ZILBERMAN, R. Literatura infantil brasileira: uma nova / outra história. Curitiba: PUCPress, FTD, 2017, com prefácio de Roger Chartier.

Entre a abertura e o fecho, - ambos voltados especificamente à literatura infantil -, são apresentadas reflexões diversas em torno de modos de leitura ou relatos de experiências a ela dedicadas. Antes da apresentação desses textos, seguem algumas reflexões sobre o processo de leitura.

Todos são unânimes em reconhecer a importância da leitura e da formação do leitor, seja na escola, seja fora dela. Autores do âmbito da Teoria Literária e da Estética da Recepção tratam da leitura, considerando-a de modo dialógico e interacional. Rifaterre (1971) menciona o leitor virtual, hipotético, ao qual o autor se dirigiria, ao escrever. Iser (1999) comenta a interação proposta pela psicologia social e aponta sua importância em diferentes ações humanas. Os críticos nomeiam vários tipos de leitor, como o leitor implícito, leitor ideal, leitor contemporâneo. Seja qualquer um deles, o ponto central é a questão da interação, do diálogo do leitor com o texto e com o autor.

A interação também é tratada por Vygotsky (2001), com outro enfoque envolvendo a própria constituição do sujeito. Para ele, o desenvolvimento do indivíduo está associado não apenas à herança genética, mas também ao convívio no contexto social, e decorre das relações cruzadas entre sociedade e indivíduo. $\mathrm{O}$ indivíduo interage pela linguagem, aprende pela linguagem, desenvolve-se pela linguagem. E quanto mais ampliar seu repertório - pelo uso da linguagem e pela leitura - mais desenvolverá as estruturas de seu pensamento.

Para ser eficaz, o trabalho com leitura deveria conceber a língua como fenômeno histórico e ideológico. Se, no passado, a leitura era considerada mera decodificação, ela passou a ser vista de outro modo, a partir das contribuições de Vygotsky e de correntes linguísticas recentes, como Linguística Textual, Análise do Discurso e Pragmática. Hoje, a leitura é vista como um processo interativo num diálogo entre autor-texto-leitor. A partir da teoria bahktiniana na qual se fundamentam, os PCNs (BRASIL, 2000) apontam que é necessário levar em conta o contexto: o leitor constrói o sentido do que lê, a partir de conhecimentos sobre o tema, o autor 
e o contexto de que faz parte ou ao qual o texto se refere. Não se pode esquecer que a linguagem mantém elos estreitos com a sociedade.

É preciso considerar que cada leitor chega ao texto munido do próprio repertório. Como os repertórios individuais diferem uns dos outros, é inevitável que um texto seja passível de mais de uma leitura ou de mais de uma interpretação. A condição para que as diferentes leituras sejam pertinentes é que se apóiem em elementos efetivamente presentes no texto lido e no seu contexto, quer em relação ao sentido explícito, quer em relação ao sentido implícito.

Um dos elementos-guia para a ação do leitor é o gênero como se observa nos PCNs (BRASIL, 2000). Nesse documento oficial, sob a influência da teoria bakhtiniana, a proposta do trabalho escolar volta-se aos enunciados concretos, em relação intrínseca com os gêneros discursivos, tanto os primários ou espontâneos - como a conversação quotidiana-, quanto os secundários ou complexos - como matérias jornalísticas, narrativas literárias, ensaios, receitas, regulamentos etc. Os gêneros discursivos são enunciados relativamente estáveis, caracterizados por três aspectos: temática, organização composicional e estilo ${ }^{1}$ (BAHKTIN, 2003). Sendo "relativamente estáveis", fica em aberto a possibilidade de eventuais instabilidades, em alguns casos. Por exemplo, quando um gênero escapa à organização composicional padrão; ou foge ao tom distanciado previsto para esse gênero, assumindo um tom envolvido com o modo de tratar o assunto; e assim por diante.

Há uma grande variedade de gêneros que, segundo pesquisadores da Universidade de Genebra (DOLZ, SCHNEUWLY et allii, 2004), podem ser reunidos em agrupamentos que circulam em determinadas esferas sociais. Também citados nos PCNs (BRASIL, 2000), Bernard Schneuwly, Joaquim Dolz e colaboradores propõem que cada agrupamento - narrar, relatar, argumentar, expor, descrever ações- circula em determinados domínios sociais da comunicação: quotidiana, escolar, burocrática, jurídica, acadêmica, científica, econômica, administrativa, de imprensa, literária e artística etc.

1 O termo 'estilo', aqui, não designa um modo de escrita individual nem de época. Neste caso, ele remete a uma característica do gênero, relacionada ao tratamento temático e à estrutura composicional. 
Pensando no foco desta edição, exemplifiquemos pelo agrupamento "narrar" ou "mimeses da ação através de intriga", próprio do domínio da cultura literária ficcional. No interior desse agrupamento, estão situados gêneros, dentre os quais: conto, fábula, lenda, novela, romance, peça teatral etc. (idem, ibidem).

Nessa concepção, os gêneros são mapeados em função do contexto em que circulam, informação que, para o leitor, seria uma primeira pista para a constituição do sentido: estamos no domínio do ficcional, da invenção. Acontecimentos que compõem o enredo, cenários, personagens, tudo o que faz parte da composição narrativa fica situado no plano da fantasia. Eles existem dentro do livro, seja impresso, seja virtual, mas não têm referente real, embora o texto possa ter sido inspirado em ocorrências, lugares e pessoas que efetivamente existem ou pareça sugerir semelhança com locais conhecidos pelo leitor.

Os autores da Universidade de Genebra, alinhados ao pensamento de Vygotsky, apresentam a seguinte tese: "o gênero é um instrumento". Por meio dele e da sequência didática - conjunto de atividades de leitura e compreensão de determinado gênero -, torna-se possível desenvolver um trabalho eficiente de formação de leitores e, complementarmente, de produtores do gênero estudado.

O rol de gêneros é constantemente renovado e ampliado. Seria impossível dar conta de todos, ao longo de alguns anos de escolaridade. A seleção de alguns a serem estudados deve ser feita em função do projeto da instituição de ensino. E, dado que o gênero é uma estratégia e uma ação, fica suposto que, a partir do trabalho escolar, o leitor em formação transfira o procedimento estratégico para as demais esferas sociais em que circule fora do âmbito escolar, num desenvolvimento permanente de um processo de formação que provavelmente perdure até o fim da vida.

Nas duas últimas décadas, multiplicou-se a presença de recursos tecnológicos dentro e fora da sala de aula. Diante dessas novas ferramentas, surgiram igualmente novas possibilidades de trabalho com leitura, dentre outros temas. Começam a ser apresentados trabalhos ilustrando esse uso, com resultados bastante animadores, desde que a tecnologia seja o meio, a ferramenta e não, a finalidade do trabalho.

Ao comentar o papel do leitor em criação de Eva Furnari, na obra Felpo Filva, Gebara e Sparano analisam uma obra de grande sucesso entre os pequenos leitores. Nela, a relação entre Charlô e Felpo problematiza o papel do leitor e do 
Linha D’Água (Online), São Paulo, v. 30, n. 2, p. 1-7, out. 2017

autor, oferecendo aos mini-leitores - termo cunhado por José Paulo Paes-, a possibilidade de entender o próprio papel e alterá-lo, descobrindo novas funções de leitor diante de cada nova leitura.

Carvalho relata uma experiência vivenciada em São Miguel Paulista. Tratase de projeto de incentivo à leitura de textos literários, desenvolvido ao longo de quatro anos (2013-2016), pela docente e por seus alunos do Curso de Letras da Universidade Cruzeiro do Sul, como parte do Festival do Livro e da Literatura do distrito de São Miguel Paulista. Na praça pública, o público era constituído por alunos de escolas públicas, além de interessados em geral. A repetição do adjetivo, na oração precedente, é intencional: ela enfatiza as condições específicas que envolvem esse projeto.

As atividades propostas no evento resgatam a tradição oral, criando um espaço lúdico para contar histórias de modo a promover reações do público, quer intelectuais, quer sensoriais, quer físicas. $\mathrm{O}$ licenciando universitário convive com alunos durante três dias, em espaço fora do ambiente escolar, em situações que possibilitam desenvolver o gosto pela leitura e a habilidade de trabalhar em equipe. Cabe ainda mencionar a responsabilidade social formadora de cidadãos conscientes.

O texto da lavra de Ramazzina Ghirardi trata do trabalho didático de transposição de textos literários impressos para novas mídias contemporâneas. Seus alunos, estudantes de graduação em Letras da Escola de Filosofia, Letras e Ciências Humanas da UNIFESP, campus Guarulhos, participaram do processo que ela descreve e comenta.

Ao longo deste editorial, frequentemente tem sido feita alusão à interação e à intertextualidade. Esse processo é ilustrado de modo contemporâneo e motivador no artigo "Letramento literário multimodal e intermidiático", explicitando em detalhes a construção do leitor/scriptor de uma nova mídia.

Os autores Peixoto Barbosa e Oliveira Simões voltam-se para o trabalho com textos jornalísticos em sala de aula, numa perspectiva enunciativo-discursiva de ensino de língua, de modo criativo e instigante. Além de discutir o letramento midiático, estendem o trabalho de interpretação e leitura para a vivência de práticas sociais próprias dessa esfera. Complementarmente, estabelecem paralelos entre o 
Linha D’Água (Online), São Paulo, v. 30, n. 2, p. 1-7, out. 2017

uso da língua portuguesa e o uso de outras linguagens, de modo a formar leitores conscientes, críticos e participativos.

Uma nova modalidade de gênero poético é abordada competentemente por Brito Neves em "Slams - letramentos literários de reexistência ao / no mundo contemporâneo". Trata-se de competições de poesia oral e performática que estão crescendo no mundo contemporâneo, dando vez e voz a poetas de periferia. Os textos são centrados em temas do quotidiano dessas áreas, em tom crítico e engajado. Dentre eles, aparecem racismo, violência, sexismo, machismo, drogas e outras questões relacionadas ao contexto local. Os "slamers" se dirigem a um público da região e atuam como agentes de letramento muito especiais, como o nosso leitor descobrirá lendo esse artigo.

A análise e a interpretação literária sob a ótica da teoria bahktiniana é o eixo do artigo de Marchezan e Pernambuco. A obra escolhida foi Mil rosas roubadas, de Silviano Santiago. Segundo Bahktin (1988), o romance não seria uma forma rígida, pois acompanha as mudanças da vida social. Ao analisar essa obra, os autores a classificam num novo gênero e se propõem a analisar a ressemantização do eu, elaborada por Silviano Santiago, no artigo "Mil rosas roubadas, de Silviano Santiago, em perspectiva bahktiniana".

O artigo de Fabrino, "Primeiros diálogos no grande tempo", propõe uma reflexão interdiscursiva sobre o texto literário, visando a uma sugestão criativa para o ensino de Literatura. Trata-se de estabelecer um diálogo entre formas atuais e formas primitivas de narrativa, os chamados "mitos da criação". Para esse paralelo, a autora se baseia no conceito bakhtiniano do diálogo no grande tempo. Propostas para o ensino da Literatura, como a apresentada neste artigo, são essenciais, pois a literatura - e a arte - podem ser reconhecidas como necessidades básicas do ser humano. Além de informação, elas exercem importante papel formador.

Consideramos que os artigos e resenha publicados neste periódico especial de Linha d'Água enriqueça o repertório de nossos leitores e leitoras e, ainda, que sejam úteis para inspirar seu trabalho docente e de pesquisador.

Nossos agradecimentos à equipe de pareceristas, revisores, tradutores que atuam para fazer de Linha d'Água uma publicação de qualidade. Agradecemos o auxílio que recebemos, por meio do Programa de Apoio às Publicações Científicas 
Linha D'Água (Online), São Paulo, v. 30, n. 2, p. 1-7, out. 2017

Periódicas da USP, Sibi - 2017, para esta edição, periódico do Programa de Filologia e Língua Portuguesa.

Para finalizar, anunciamos que a partir desse número, a revista encontra-se indexada na importante base de dados internacional Web of Science. Esse trabalho é o resultado de um enorme esforço em parceria com o Sistema Integrado de Bibliotecas da USP/ Sibi.

Outubro, 2017.

\section{Referências}

BAKHTIN, M. Estética da criação verbal. Trad. Paulo Bezerra. 4 ed. São Paulo: Martins Fontes, 2003.

Questôes de literatura e de estética. A teoria do romance. Trad. Aurora Fornoni Bernardini et al. São Paulo: Unesp, Hucitec. 1988.

BRASIL (SEF / MEC) Parâmetros Curriculares nacionais: terceiro e quarto ciclos: lingua portuguesa. Secretaria de Educação Fundamental. 2 ed. 2000.

DOLZ, J., SCHNEUWLY, B. et allii. Gêneros orais e escritos na escola. Tradução e seleção de Roxane Rojo e Glais Sales Cordeiro. Campinas, Mercado de Letras, 2004.

ISER, W. O ato da leitura. Uma teoria do efeito estético. Trad. Johannes Kretschmer. São Paulo: Editora 34, 1999, 2 volumes.

RIFATERRE, M. Estilistica estrutural. Trad. Anne Arnichand; Álvaro Lorencini. São Paulo; Editora Cultrix, 1973.

VYGOTSKY, L.S. Pensamento e linguagem. Versão digital para e-book, 2001. Edição Ridendo Castigat Mores. Disponível em http://www.ebooksbrasil.org/eLibris/vigo.html. Acesso em 10 mai. 2017. 